\title{
Determinants of Ownership and Utilization of Insecticide-Treated Bed Nets for Malaria Control in Eastern Ethiopia
}

\author{
Sibhatu Biadgilign, ${ }^{1}$ Ayalu Reda, ${ }^{2}$ and Haji Kedir ${ }^{2,3}$ \\ ${ }^{1}$ Department of Epidemiology and Biostatistics, College of Public Health and Medical Sciences, Jimma University, \\ P.O. Box 24414, Jimma, Ethiopia \\ ${ }^{2}$ Department of Public Health, College of Health Sciences, Haramaya University, P.O. Box 1014, Harar, Ethiopia
}

${ }^{3}$ Addis Continental Institute of Public Health, P.O. Box 1014, Addis Ababa, Ethiopia

Correspondence should be addressed to Sibhatu Biadgilign, sibhatu2005@yahoo.com

Received 10 June 2012; Revised 21 September 2012; Accepted 14 October 2012

Academic Editor: Blaise Genton

Copyright () 2012 Sibhatu Biadgilign et al. This is an open access article distributed under the Creative Commons Attribution License, which permits unrestricted use, distribution, and reproduction in any medium, provided the original work is properly cited.

Background. Malaria remains a major cause of mortality and morbidity in the world, and particularly in sub-Saharan Africa. Objectives. The aim of this study was to determine ownership and utilization of ITNs among households with children under five in the previous night. Methods. A community based cross-sectional study was conducted in Gursum district in Eastern Ethiopia. A total of 335 households were surveyed using a pretested structured questionnaire administered though house-to-house interviews. Results. Household ownership for at least one mosquito net and use of nets were 62.4\% (95\% CI 57.2-67.6\%) and 21.5\% (95\% CI 17.1-25.9\%), respectively. Households who received or were told about ITN in the last 6 months were three times more likely to have used it than those who were not (OR 3.25; 95\% CI 1.5-7.10). Households whose heads were engaged as a farmer (adjusted OR 0.137; 95\% CI: 0.04-0.50) and housewife (OR 0.26; 95\% CI: 0.08-0.82) were less likely to use ITN than those of other occupations. Conclusion. The findings indicate low ITN ownership and utilization among the households. Intensive health education and community mobilization effort should be employed to increase the possession and proper utilization of insecticide treated bed nets.

\section{Background}

The World Health Organization (WHO) estimated that the number of cases of malaria rose from 233 million in 2000 to 244 million in 2005 but decreased to 225 million in 2009. The number of deaths due to malaria is estimated to have decreased from 985,000 in 2000 to 781,000 in 2009 [1]. Malaria remains a major public health problem particularly in sub-Saharan Africa [2] which accounts for about 90 per cent of all malaria deaths, most among children under age five [3]. Malaria-related mortality, morbidity, and economic loss could be averted if the available effective preventive and treatment interventions were made universally accessible to those in need [4]. In Africa about one out of every twenty children is likely to die of malaria-related illness before their fifth birthday [5].
In Ethiopia, malaria transmission is highly seasonal and often takes epidemic forms where significantly higher malaria morbidity and mortality occurs during the peak transmission season from September to December. Even though all age groups are at risk of developing severe malaria, children and pregnant women are the most vulnerable [6]. Approximately $75 \%$ of Ethiopia's landmass is malaria endemic [7-9]. The coverage and proper utilization of the most promising malaria preventive measure, insecticidetreated bed nets (ITNs), in the country is also limited due to lack of sustainable distribution and issues related to replacement of nets, seasonality of malaria, and poor knowledge of the community with regard to the link between mosquitoes and malaria [10].

The Roll Back Malaria (RBM) has identified under-five children as one of the highest risk groups for malaria, and 
one of the strategies set to fight malaria in this group is to increase utilization of mosquito nets [11]. The use of insecticide-treated mosquito nets (ITNs) is a cost-effective intervention to reduce child mortality and maternal anemia where malaria imposes an important disease burden [12]. Roll Back Malaria (RBM) campaign targets to have $80 \%$ of pregnant women and children under five covered by insecticide-treated bed nets (ITN) by 2010 [13].

Identification of awareness gaps, monitoring of behavioral changes on malaria disease recognition and use of preventive and control measures such as the use of ITNs are a priority area for the government of Ethiopia with a special emphasis on increasing coverage and use of ITNs under national malaria guidelines [14]. Few studies assessed the ownership and use of ITNs by households of under-five children. This paper describes household ownership and utilization of ITNs in the previous night among this vulnerable group in a malaria-prone rural district in eastern Ethiopia.

\section{Methods}

2.1. Study Setting and Participants. A community-based cross-sectional study was conducted in Gursum district, eastern Ethiopia in January 2008. This rural town district had a total population of 12,027 . It was purposely selected for this study because it is among the major malaria-prone areas of eastern Ethiopia. The mean/median altitude of the study district ranges from 1200 to 2950 meters above sea level. The source population included all households with children under five years of age. Households were randomly selected from a list provided by the district administration. The sample size was calculated by using the formula for a single population proportion considering the assumption 95\% CI and 5\% margin error and prevalence of ITN use as 50\%. This gives a final sample size of 384 . Health extension workers (HEW) distributed the Long lasting insecticide-treated net (LLIN) to the community at their vicinity/households in a procedure of free mass distribution campaigns. The study was conducted from February to March 2006.

2.2. Questionnaire and Data Collection. Data were collected using a pretested structured questionnaire prepared in English and then translated into the local language of Oromiffa. The questionnaire was adopted from instruments developed by the Roll Back Malaria (RBM) partnership monitoring and evaluation reference Group by the WHO and UNICEF [15]. It included variables related to sociodemographic characteristics, number of household members, net possession, net utilization, and so forth. Pretest was carried out on $5 \%$ of the households. Necessary modifications were made thereafter. Final year public health professionals administered the questionnaire through house to house visits. Information was primarily collected from the heads of the households (father or mother) or from an adult household member in case this was not possible.

2.3. Operational Definitions. Households were considered ITN owners if they had at least one ITN at the time of the interview. Children that were reported to have slept under an ITN in the night prior to the survey interview were considered as users.

2.4. Statistical Analysis. Data were checked for completeness and consistency. The data were entered at once by a trained data manager. Coded data were entered, cleaned, and analyzed using SPSS version 16.0 for Windows (SPSS, Chicago, IL, USA). Descriptive summaries (frequencies and proportions) and univariate analysis were calculated. Multivariable logistic regression analysis was used for determining ITN ownership and utilization as the main outcome variables. Unadjusted and adjusted odds ratios (AOR) and their corresponding $95 \%$ confidence intervals (CI) were used to examine the strength of association. $P$ values of less or equal to 0.05 were considered significant.

2.5. Ethical Clearance. Ethical clearance was obtained from Haramaya University, Faculty of Health Sciences Institutional Research Ethics Review Committee. Verbal consent was obtained from individual respondents.

\section{Results}

3.1. Sociodemographic Characteristics of the Study Population. A total of 335 households participated in this study with a response rate of $88 \%$. The mean (SD) family size of the households was 5.45 (2.85) with a median of 5 . The majority $(247,73.7 \%)$ of the respondents were females, while 228 (68.1\%) were illiterate (see Table 1).

3.2. Insecticide-Treated Bed Net (ITN) Ownership and Utilization. Household ownership for at least one mosquito net in the surveyed households was found to be 209 (62.4\%; 95\% CI $57.2-67.6 \%)$. Eighty seven (41.6\%) and 116 (55.5\%) households owned one and two nets, respectively. The nets were obtained from the district health office $(96,45.9 \%)$ and the local health center $(32,15.3 \%)$ for free and from other sources $(52,24.9 \%)$. Sixty households $(28.7 \%)$ and 90 (43.1\%) reported to have obtained the ITNs 6-12 months and 13-24 months, respectively, prior to the time of the survey (Table 2). Forty five (21.5\%; 95\% CI $17.1-25.9 \%)$ of the surveyed households utilized bed nets.

3.3. Knowledge and History of Malaria in the Past One Year. Among the households studied, in $81(24.2 \%)$ at least one family member had symptoms of malaria in the past one year. The signs and symptoms reported were fever 80 $(23.9 \%)$, chills $(77,23.0 \%)$, and headache $(75,22.4 \%)$. The majority got treatment from government health facilities $(65$, $81.2 \%)$ and private clinics $(12,15.0 \%)$. The most important sources of information on malaria cited by respondents were mass media $(148,48.5 \%)$, health workers $(87,28.5 \%)$, local village leaders $(16,5.2 \%)$, health extensions workers (24, $7.97 \%)$, and neighbors (30, 9.83\%). About 58 (17.3\%) households had a family member that traveled outside the district in the month prior to the survey (Table 3). 
TABLE 1: Sociodemographic characteristics of respondents in Gursum district, Ethiopia, 2008.

\begin{tabular}{|c|c|c|}
\hline Variables & Frequency & Percentage \\
\hline \multicolumn{3}{|l|}{ Sex } \\
\hline Male & 88 & 26.3 \\
\hline Female & 247 & 73.7 \\
\hline \multicolumn{3}{|l|}{ Religion } \\
\hline Christian & 51 & 15.2 \\
\hline Muslim & 284 & 84.8 \\
\hline \multicolumn{3}{|l|}{ Marital status } \\
\hline Single & 16 & 4.8 \\
\hline Married & 287 & 85.7 \\
\hline Divorced & 12 & 3.6 \\
\hline Widowed & 16 & 4.8 \\
\hline Separated & 4 & 1.2 \\
\hline \multicolumn{3}{|l|}{ Occupational status } \\
\hline Farmer & 104 & 31.0 \\
\hline Student & 26 & 7.8 \\
\hline House wife & 149 & 44.5 \\
\hline Government employee & 12 & 3.6 \\
\hline Merchant & 39 & 11.6 \\
\hline Others* & 5 & 1.5 \\
\hline \multicolumn{3}{|l|}{ Educational level } \\
\hline Illiterate & 228 & 68.1 \\
\hline Read and write only & 16 & 4.8 \\
\hline Primary education (1-6) & 40 & 11.9 \\
\hline Secondary education (7-12) & 32 & 9.6 \\
\hline Above grade 12 & 19 & 5.7 \\
\hline \multicolumn{3}{|l|}{$\begin{array}{l}\text { Estimated monthly income of the } \\
\text { household (USD per month) }\end{array}$} \\
\hline$<10.4$ & 133 & 39.7 \\
\hline $10.4-31.14$ & 103 & 30.7 \\
\hline $31.25-51.98$ & 35 & 10.4 \\
\hline $52.08-83.33$ & 38 & 11.3 \\
\hline$>83.33$ & 26 & 7.8 \\
\hline
\end{tabular}

* Others: sales and services, clerk.

\$Exchange rate at the time of the study, 1 USD $=9.6$ Ethiopian Birr (ETB).

3.4. Determinants of ITN Ownership and Utilization. Households whose heads were farmers were five times more likely to have owned ITNs than those whose heads were traders (AOR 5.11; 95\% CI 1.88-13.94). Households with respondents that knew the cause of malaria were twice more likely to have owned ITNs than those who did not know (AOR 2.64; 95\% CI 1.31-5.30). Those who ever heard about ITN were seven times more likely to have owned one than those that did not (AOR 7.56; 95\% CI: 1.95-29.28). Households whose family size was less than 3 were $77 \%$ less likely to have owned ITNs than those of seven or more family size (AOR 0.23; $95 \%$ CI: 0.10-0.52) (Table 4).

Those households who received or were told about ITN in the last 6 months prior to the survey were three times more likely to have used it than those who were not (AOR 3.25;
TABLE 2: Mosquito net ownership and utilization among respondents in Gursum district, Ethiopia, 2008.

\begin{tabular}{lcc}
\hline Variables & Frequency & Percentage \\
\hline Is there a bed net in your house & & \\
$\quad$ Yes & 209 & 62.4 \\
$\quad$ No & 126 & 37.6 \\
The number of nets in the household & & \\
$\quad$ 1 net & 87 & 41.6 \\
2 nets & 116 & 55.5 \\
3 nets and more & 6 & 2.9 \\
Where did you get it? & & \\
Health office & 96 & 45.9 \\
Health center & 32 & 15.3 \\
Health post/clinic & 12 & 5.7 \\
Shops & 17 & 8.1 \\
Other & 52 & 24.9 \\
When did you obtain it (in months)? & & \\
$\quad<6$ months & 16 & 7.7 \\
6-12 months & 60 & 28.7 \\
13-24 months & 90 & 43.1 \\
$>24$ months & 43 & 20.6 \\
ITN utilization & & \\
Yes & 45 & 21.5 \\
No & 164 & 78.5 \\
\hline
\end{tabular}

95\% CI 1.5-7.10). Households whose family size was less than or equal to four were two times more likely to have used ITNs than those whose family size of greater than four (AOR 2.32; 95\% CI 1.06-5.05). Occupationally, those households whose heads were engaged as a farmer (AOR 0.14; 95\% CI: 0.04-0.50) and housewife (AOR 0.26; 95\% CI: 0.08-0.82) were less likely to use ITNs than those of traders (Table 5).

\section{Discussion}

The World Health Assembly and the Roll Back Malaria (RBM) partnership in 2005 set the goal of reducing the numbers of malaria cases and deaths recorded in 2000 by $75 \%$ or more by the end of 2015 [1]. There has been a noticeable increase in international funding for malaria control in the past decade. This increased financing has led to tremendous progress in increasing access to insecticide-treated mosquito nets (ITNs). It is reported that by the end of 2010, approximately 289 million ITNs were delivered to sub-Saharan Africa, about enough to cover $76 \%$ of the 765 million persons that are at risk of malaria [1].

This study aimed to assess ownership and utilization of bed nets in a rural town of eastern Ethiopia. Our finding indicates an ITN ownership of $62.4 \%$ (95\% CI $57.2-67.6 \%)$. It is estimated that $42 \%$ of households in Africa owned at least one ITN in mid-2010, and that $35 \%$ of children slept under it [1]. The percentage of children using ITNs is still below the World Health Assembly target of $80 \%$ partly because up 
TABLE 3: Malaria knowledge and history in the past one year among respondents in Gursum district, Ethiopia, 2008.

\begin{tabular}{|c|c|c|}
\hline Variables & Frequency & Percentage \\
\hline \multicolumn{3}{|c|}{$\begin{array}{l}\text { Has anyone in your family caught malaria } \\
\text { in the past one year? }\end{array}$} \\
\hline Yes & 81 & 24.2 \\
\hline No & 254 & 75.8 \\
\hline \multicolumn{3}{|c|}{$\begin{array}{l}\text { If yes, what were the signs and symptoms } \\
\text { he/she was experiencing? }\end{array}$} \\
\hline Fever & 80 & 23.9 \\
\hline Chills & 77 & 23.0 \\
\hline Headache & 75 & 22.4 \\
\hline Backache and generalized aching & 58 & 17.3 \\
\hline Convulsion & 29 & 8.7 \\
\hline Loss of consciousness (coma) & 26 & 7.8 \\
\hline \multicolumn{3}{|l|}{$\begin{array}{l}\text { Place of treatment among households } \\
\text { who faced malaria }\end{array}$} \\
\hline Government health facility & 65 & 81.2 \\
\hline Private clinic & 12 & 15.0 \\
\hline Traditional healer & 2 & 2.5 \\
\hline Buy drug from any shop & 1 & 1.2 \\
\hline \multicolumn{3}{|l|}{$\begin{array}{l}\text { Did anyone in your family travel away } \\
\text { from home in the last one month? }\end{array}$} \\
\hline Yes & 58 & 17.3 \\
\hline No & 277 & 82.7 \\
\hline \multicolumn{3}{|l|}{ Did she/he use ITN while on travel } \\
\hline Yes & 12 & 3.6 \\
\hline No & 323 & 96.4 \\
\hline \multicolumn{3}{|l|}{ Source of information for ITN } \\
\hline Mass media & 148 & 48.5 \\
\hline Health workers & 87 & 28.5 \\
\hline Kebele leader & 16 & 5.2 \\
\hline Health extensions workers & 24 & 7.97 \\
\hline Neighborhood & 30 & 9.83 \\
\hline
\end{tabular}

to the end of 2009, ITN ownership remained low in some of the largest African countries.

Low rates of use reported in surveys are primarily due to lack of sufficient nets to cover all household members; household survey results suggest that most $(80 \%)$ of the available ITNs are used [1]. According to a malaria indicator survey conducted in 2007 among 5,083, in Ethiopia, 65.6\% of households residing in malaria-prone areas owned at least one ITN [16]. Similarly, in malaria-prone areas, ITN use by children under five years and pregnant women has remarkably leapt from $2.8 \%$ and $1.6 \%$ to $41.2 \%$ and $42.5 \%$, respectively, in 2005 [17]. In MIS 2007, a total of 14,663 participants in 3,353 households owned nets. Despite an increase in the proportion of households owning at least one net, a lower proportion of participants (50.9\%) reported using nets the previous night during MIS 2007 [18]. Household possession for at least one mosquito net in the surveyed households was found to be $748(90.3 \%)$ and household possession for at least one insecticide-treated bed net was found to be $708(85.5 \%)$ [19]. In our study, $62.4 \%$ of households had at least one ITN. In a study carried out by Baume et al., of 857 surveyed households, 780 (91\%) owned at least one ITN in Oromia and Amhara regions of Ethiopia. 63\% of ITN-owning households owned more than one ITN [20]. Household ownership of any net was $23.9 \%$ (95\% CI 22.8\%$25.1 \%$ ) and $10.1 \%$ for ITNs (95\% CI 9.2\%-10.9\%). Utilization of any net by children under five was $11.5 \%$ (95\% CI $10.4 \%-12.6 \%)$ and $1.7 \%$ (95\% CI 1.3\%-2.2\%) for ITN [21]. The utilization of ITN in our study is $45(21.5 \%)$. Fegan et al., found that consistent use of ITNs can reduce malaria transmission by up to $90 \%$ and avert as much as $44 \%$ of allcause mortality in their study of under-five children in rural Kenya [22].

Occupational status of the household head and family size were among the factors affecting the ownership of ITN in our study. Similar findings have been documented in other studies. In one study in Ethiopia, government employees and self-employed traders were less likely to own a net [19]. In our study, family size was associated with the possession of net. Similarly in Tanzania a unit increase in family size increased the odds of ownership of a net more than twice while controlling for all other variables, where for households who had at least one under-five child the odds of owning any net was about $60 \%$ higher than those with no under-five children [21]. In another study, women's and head of household's education, head of household's occupation, marital status, household size, household wealth, living in rural areas, and expenditure on other malaria prevention products and practices were found to be associated with ITN ownership [23-25].

A strong association remained between using ITNs, owning a radio, and living close to a health institution [26]. In addition, households' desire for mosquito avoidance and correct knowledge of malaria transmission were reported to be strong determinants of ITN usage [27, 28]. The acquisition and usage of untreated mosquito nets was low and nil for ITNs and very few people had heard about ITNs [29]. The results are also similar to the findings in Mozambique, where only $3 \%$ of people had heard about ITNs and 9\% used treated or ordinary nets [30]. In one study in Ethiopia, it was found that the role of health workers was minimal in delivering health education regarding the importance and proper use of nets. Instead, radio played a dominant role for the dissemination of information on ITNs as it has been reported in another study [31].

Several studies suggest that perceived malaria risk and malaria knowledge are important determinants of bed net ownership and use $[25,32,33]$. For instance, knowledge of malaria amongst mothers of under-five children was associated with ITN use for their children [34]. Factors significantly associated with ITN use were women's knowledge of ITNs and women's lack of problem in using ITNs [35]. However, other studies have reported that greater malaria knowledge, education, and wealth are not consistent determinants of net use [36-38]. It is found that while net replacement remains important, the more education about use and care of nets are likely to increase the use of nets by households [39]. It is also worth mentioning that even when knowledge 
TABLE 4: Final logistic regression model for household's ownership of ITNs (with estimated odds ratios) in Gursum district, Ethiopia, 2008.

\begin{tabular}{|c|c|c|c|c|c|c|}
\hline \multirow{2}{*}{ Variables } & \multicolumn{2}{|c|}{ Ownership of ITN } & \multirow{2}{*}{ Crude OR (95\% CI) } & \multirow{2}{*}{$P$ value } & \multirow{2}{*}{ Adjusted OR (95\% CI) } & \multirow{2}{*}{$P$ value } \\
\hline & Yes $n(\%)$ & No $n(\%)$ & & & & \\
\hline \multicolumn{7}{|l|}{ Occupation } \\
\hline Farmer & $80(8.3)$ & $24(19.0)$ & $4.71(2.18-10.17)$ & \multirow{5}{*}{0.001} & $5.11(1.88-13.94)$ & \multirow{5}{*}{0.026} \\
\hline Student & $19(9.1)$ & $9(7.1)$ & $2.98(1.09-8.16)$ & & $2.53(0.71-8.96)$ & \\
\hline Housewife & $85(40.7)$ & $64(50.8)$ & $1.87(0.93-3.78)$ & & $2.10(0.87-5.06)$ & \\
\hline Government employee & $8(3.8)$ & $5(4.0)$ & $2.26(0.63-8.11)$ & & $1.46(0.27-7.91)$ & \\
\hline Merchant & $17(8.1)$ & $24(19.0)$ & 1.00 & & 1.00 & \\
\hline \multicolumn{7}{|c|}{ Knowledge of the cause of malaria } \\
\hline Yes & $179(85.6)$ & $77(61.1)$ & $3.80(2.24-6.43)$ & \multirow{2}{*}{0.000} & $2.64(1.31-5.30)$ & \multirow{2}{*}{0.007} \\
\hline No & $30(14.4)$ & $49(38.9)$ & 1.00 & & 1.00 & \\
\hline \multicolumn{7}{|c|}{ Feeling family is at risk of getting malaria } \\
\hline Yes & $111(55.8)$ & $84(70.6)$ & $0.53(0.32-0.85)$ & \multirow{2}{*}{0.009} & $0.33(0.17-0.69)$ & \multirow{2}{*}{0.001} \\
\hline No & $88(44.2)$ & $35(29.4)$ & 1.00 & & 1.00 & \\
\hline \multicolumn{7}{|c|}{ Have you ever heard about ITN } \\
\hline Yes & $199(97.5)$ & $106(88.3)$ & $5.26(1.84-15.0)$ & \multirow{2}{*}{0.002} & $7.56(1.95-29.28)$ & \multirow{2}{*}{0.003} \\
\hline No & $5(2.5)$ & $14(11.7)$ & 1.00 & & 1.00 & \\
\hline \multicolumn{7}{|l|}{ Family size } \\
\hline Less than 3 & $38(18.2)$ & $56(44.4)$ & $0.20(0.11-0.38)$ & \multirow{4}{*}{0.000} & $0.23(0.10-0.52)$ & \multirow{4}{*}{0.001} \\
\hline Four & $36(17.2)$ & $22(17.5)$ & $0.49(0.24-0.99)$ & & $1.05(0.41-2.68)$ & \\
\hline Five and six & $58(27.8)$ & $25(19.8)$ & $0.69(0.36-1.34)$ & & $0.81(0.36-1.82)$ & \\
\hline Seven and above & $77(36.8)$ & $23(18.3)$ & 1.00 & & 1.00 & \\
\hline
\end{tabular}

TABLE 5: Final logistic regression model for household's ITNs use (with estimated odds ratios) in Gursum district, Ethiopia, 2008.

\begin{tabular}{|c|c|c|c|c|c|c|}
\hline \multirow{2}{*}{ Variables } & \multicolumn{2}{|c|}{ ITN Utilization status } & \multirow{2}{*}{ Crude OR (95\% CI) } & \multirow{2}{*}{$P$ value } & \multirow{2}{*}{ Adjusted OR (95\% CI) } & \multirow{2}{*}{$P$ value } \\
\hline & Yes $n(\%)$ & No $n(\%)$ & & & & \\
\hline \multicolumn{7}{|c|}{ Ever heard about ITN in the last 6 months } \\
\hline Yes & $28(63.6)$ & $49(31.0)$ & $3.89(1.93-7.84)$ & \multirow{2}{*}{0.000} & $3.25(1.50-7.06)$ & \multirow{2}{*}{0.003} \\
\hline No & $16(36.4)$ & $109(69.0)$ & 1.00 & & 1.00 & \\
\hline \multicolumn{7}{|l|}{ Family size } \\
\hline$\leq 4$ & $25(55.6)$ & $49(29.9)$ & $2.93(1.49-5.77)$ & \multirow{2}{*}{0.002} & $2.32(1.06-5.05)$ & \multirow{2}{*}{0.034} \\
\hline$>4$ & $20(44.4)$ & $115(70.1)$ & 1.00 & & 1.00 & \\
\hline \multicolumn{7}{|l|}{ Occupation } \\
\hline Farmer & $7(15.6)$ & $73(44.5)$ & $0.11(0.03-0.37)$ & \multirow{5}{*}{0.000} & $0.14(0.04-0.50)$ & \multirow{5}{*}{0.006} \\
\hline Student & $9(20.0)$ & $10(6.1)$ & $1.01(0.27-3.75)$ & & $0.75(0.18-3.08)$ & \\
\hline Housewife & $16(35.6)$ & $69(42.1)$ & $0.26(0.09-0.78)$ & & $0.26(0.08-0.82)$ & \\
\hline Government employee & $5(11.1)$ & $3(1.8)$ & $1.87(0.34-10.46)$ & & $0.93(0.15-5.82)$ & \\
\hline Merchant & $8(17.8)$ & $9(5.5)$ & 1.00 & & 1.00 & \\
\hline
\end{tabular}

is a predictor of ITN use; it may not assure protection from malaria unless there is proper use and strong adherence.

The limitation of this study was that we used selfreported ownership and use of ITNs by households without verification and net factors such as color, shape, age. One of the strengths of this study is that we investigated an important group of malaria victims.

\section{Conclusion}

We conclude that there is low ITN ownership and utilization among the households. The majority of them were obtained from governmental health facilities. Enhanced health education and community mobilization efforts should be employed to increase the possession and proper utilization of insecticide-treated bed nets. The government should redistribute ITNs in the area to increase the coverage and conduct mass education to increase their utilization among the households.

\section{Conflict of Interests}

The authors declare that they have no conflict of interests. 


\section{Authors' Contributions}

S. Biadgilign conceived and designed the study, performed analysis and interpretation of data, and drafted the paper. A. A. Reda and H. Kedir assisted with the design, interpretation of data, and the critical review of the paper. All authors approved and read the final paper.

\section{Acknowledgment}

The authors thank Haramaya University for funding the study. Their appreciation also extends to staffs of the same University, data collectors, supervisors, and study participants. The funding body had no role in the study design; analysis and interpretation of data or the writing and submission of this paper for publication.

\section{References}

[1] WHO, World Malaria Report 2010, World Health Organization, Geneva, Switzerland, 2010.

[2] Roll Back Malaria, "The Africa malaria," 2006, http://www. rbm.who.int/.

[3] WHO, World Malaria Report 2008, World Health Organization, Geneva, Switzerland, 2008.

[4] J. G. Breman, M. S. Alilio, and N. J. White, "Defining and defeating the intolerable burden of malaria III. Progress and perspectives," American Journal of Tropical Medicine and Hygiene, vol. 77, supplement 6, 2007.

[5] Roll Back Malaria, "Malaria in Pregnancy," http://www.rbm. who.int/cmc_upload/0/000/015/369/RBMInfosheet_4.htm.

[6] W. Deressa and A. Ali, "Malaria-related perceptions and practices of women with children under the age of five years in rural Ethiopia," BMC Public Health, vol. 9, article 259, 2009.

[7] T. Adhanom, W. Deressa, K. H. Witten, A. Getachew, and T. Seboxa, "Malaria.," in Epidemiology and Ecology of Health and Disease in Ethiopia, Y. Berhane, D. Haile-Mariam, and H. Kloos, Eds., pp. 556-576, Shama Books, Addis Ababa, Ethiopia, 1st edition, 2006.

[8] T. A. Ghebreyesus, M. Haile, K. H. Witten et al., "Household risk factors for malaria among children in the Ethiopian highlands," Transactions of the Royal Society of Tropical Medicine and Hygiene, vol. 94, no. 1, pp. 17-21, 2000.

[9] I. Peterson, L. N. Borrell, W. El-Sadr, and A. Teklehaimanot, "Individual and household level factors associated with malaria incidence in a highland region of Ethiopia: a multilevel analysis," American Journal of Tropical Medicine and Hygiene, vol. 80, no. 1, pp. 103-111, 2009.

[10] MOH, Proceedings of the National Workshop on the Review of the First Five-Year (2001-2005) and Preparation of the Second Five-Year (2006-2010) National Strategic Plan For Malaria Prevention and Control in Ethiopia, Federal Democratic Republic of Ethiopia Ministry of Health, Addis Ababa, Ethiopia, 2006.

[11] UNICEF, WHO, RBM, and MEASURE Evaluation, Guidelines For Core Population Coverage Indicators For Roll Back Malaria, UNICEF, 2004.

[12] K. Hanson, R. Nathan, T. Marchant et al., "Vouchers for scaling up insecticide-treated nets in Tanzania: methods for monitoring and evaluation of a national health system intervention," BMC Public Health, vol. 8, article 205, 2008.

[13] Roll Back Malaria, Global Strategic Plan: Roll Back Malaria, 2005-2015, Roll Back Malaria Partnership, WHO, Geneva, Switzerland, 2005.
[14] Federal Ministry of Health, National Malaria Guidelines, Federal Ministry of Health, Addis Ababa, Ethiopia, 3rd edition, 2012.

[15] Roll Back Malaria, MEASURE Evaluation, World Health Organization, and UNICEF, Guidelines For Core Population Coverage Indicators For Roll Back Malaria: To Be Obtained From Household Surveys, MEASURE Evaluation, Calverton, Md, USA, 2006.

[16] D. Jima, A. Getachew, H. Bilak et al., "Malaria indicator survey 2007, Ethiopia: coverage and use of major malaria prevention and control interventions," Malaria Journal, vol. 9, no. 1, article 58, 2010.

[17] FMOH/MOH, "Health Sector Development Program IV, 2010/11-2014/15," Final draft October 2010.

[18] P. M. Graves, J. M. Ngondi, J. Hwang et al., "Factors associated with mosquito net use by individuals in households owning nets in Ethiopia," Malaria Journal, vol. 10, article 354, 2011.

[19] B. Haileselassie and A. Ali, "Assessment of insecticide treated nets coverage for Malaria control in kafta-humera district, Tigray: possession versus use by high-risk groups," The Ethiopian Journal of Health Development, vol. 22, no. 3, pp. 259-267, 2008.

[20] C. A. Baume, R. Reithinger, and S. Woldehanna, "Factors associated with use and non-use of mosquito nets owned in Oromia and Amhara Regional States, Ethiopia," Malaria Journal, vol. 8, no. 1, article 264, 2009.

[21] O. B. Oresanya, M. Hoshen, and O. T. Sofola, "Utilization of insecticide-treated nets by under-five children in Nigeria: assessing progress towards the Abuja targets," Malaria Journal, vol. 7, article 145, 2008.

[22] G. W. Fegan, A. M. Noor, W. S. Akhwale, S. Cousens, and R. W. Snow, "Effect of expanded insecticide-treated bednet coverage on child survival in rural Kenya: a longitudinal study," The Lancet, vol. 370, no. 9592, pp. 1035-1039, 2007.

[23] F. Matovu, C. Goodman, V. Wiseman, and W. Mwengee, "How equitable is bed net ownership and utilisation in Tanzania? A practical application of the principles of horizontal and vertical equity," Malaria Journal, vol. 8, no. 1, article 109, 2009.

[24] A. Pettifor, E. Taylor, D. Nku et al., "Bed net ownership, use and perceptions among women seeking antenatal care in Kinshasa, Democratic Republic of the Congo (DRC): opportunities for improved maternal and child health," BMC Public Health, vol. 8, article 331, 2008.

[25] V. Wiseman, A. Scott, B. McElroy, L. Conteh, and W. Stevens, "Determinants of bed net use in The Gambia: Implications for malaria control," American Journal of Tropical Medicine and Hygiene, vol. 76, no. 5, pp. 830-836, 2007.

[26] J. Paulander, H. Olsson, H. Lemma, A. Getachew, and M. San Sebastian, "Knowledge attitudes and practice about malaria in rural Tigray, Ethiopia," Global Health Action, vol. 2, pp. 499507, 2009.

[27] I. A. Agyepong and L. Manderson, "Mosquito avoidance and bed net use in the Greater Accra Region, Ghana," Journal of Biosocial Science, vol. 31, no. 1, pp. 79-92, 1999.

[28] F. N. Binka and P. Adongo, "Acceptability and use of insecticide impregnated bednets in northern Ghana," Tropical Medicine and International Health, vol. 2, no. 5, pp. 499-507, 1997.

[29] O. Onwujekwe, B. Uzochukwu, N. Ezumah, and E. Shu, "Increasing coverage of insecticide-treated nets in rural Nigeria: Implications of consumer knowledge, preferences and expenditures for malaria prevention," Malaria Journal, vol. 4, no. 1 , article 29, 2005.

[30] F. S. Mbofana, "Use of insecticide-treated nets in Inharrime and Zavala districts, Mozambique: knowledge, availability, 
affordability and acceptability," in Proceedings of The 3rd MIM Pan-African Malaria Conference, p. 287, Arusha, Tanzania, 2002.

[31] A. Animut, T. Gebre-Michael, G. Medhin, M. Balkew, S. Bashaye, and A. Seyoum, "Assessment of distribution, knowledge and utilization of insecticide treated nets in selected malaria prone areas of ethiopia," The Ethiopian Journal of Health Development, vol. 22, no. 3, pp. 268-274, 2008.

[32] J. Okrah, C. Traoré, A. Palé, J. Sommerfeld, and O. Müller, "Community factors associated with malaria prevention by mosquito nets: an exploratory study in rural Burkina Faso," Tropical Medicine and International Health, vol. 7, no. 3, pp. 240-248, 2002.

[33] P. Opiyo, W. R. Mukabana, I. Kiche, E. Mathenge, G. F. Killeen, and U. Fillinger, "An exploratory study of community factors relevant for participatory malaria control on Rusinga Island, western Kenya," Malaria Journal, vol. 6, article 48, 2007.

[34] J. Hwang, P. M. Graves, D. Jima et al., "Knowledge of malaria and its association with malaria-related behaviors-results from the Malaria Indicator Survey, Ethiopia, 2007," PLoS One, vol. 5, no. 7, Article ID e11692, 2010.

[35] W. Deressa, G. Fentie, S. Girma, and R. Reithinger, "Ownership and use of insecticide-treated nets in Oromia and Amhara Regional States of Ethiopia two years after a nationwide campaign," Tropical Medicine and International Health, vol. 16, no. 12, pp. 1552-1561, 2011.

[36] J. A. Alaii, W. A. Hawley, M. S. Kolczak et al., "Factors affecting use of permethrin-treated bed nets during a randomized controlled trial in Western Kenya," American Journal of Tropical Medicine and Hygiene, vol. 68, no. 4, pp. 137-141, 2003.

[37] N. de la Cruz, B. Crookston, K. Dearden et al., "Who sleeps under bednets in Ghana? A doer/non-doer analysis of malaria prevention behaviours," Malaria Journal, vol. 5, article 61, 2006.

[38] T. P. Eisele, J. Keating, M. Littrell, D. Larsen, and K. Macintyre, "Assessment of insecticide-treated bednet use among children and pregnant women across 15 countries using standardized national surveys," American Journal of Tropical Medicine and Hygiene, vol. 80, no. 2, pp. 209-214, 2009.

[39] J. M. Ngondi, P. M. Graves, T. Gebre et al., "Which nets are being used: factors associated with mosquito net use in Amhara, Oromia and Southern Nations, Nationalities and Peoples' Regions of Ethiopia," Malaria Journal, vol. 10, article 92, 2011. 


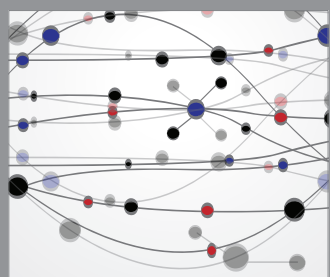

The Scientific World Journal
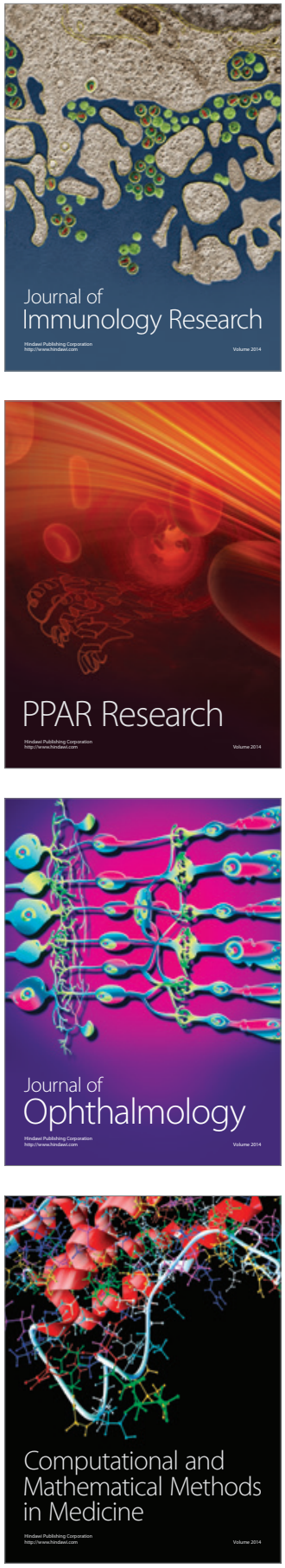

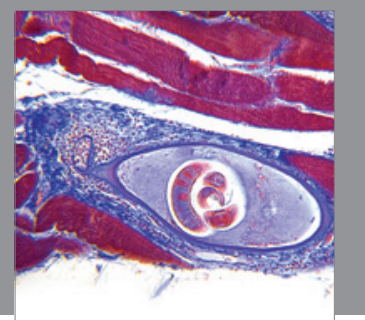

Gastroenterology

Research and Practice
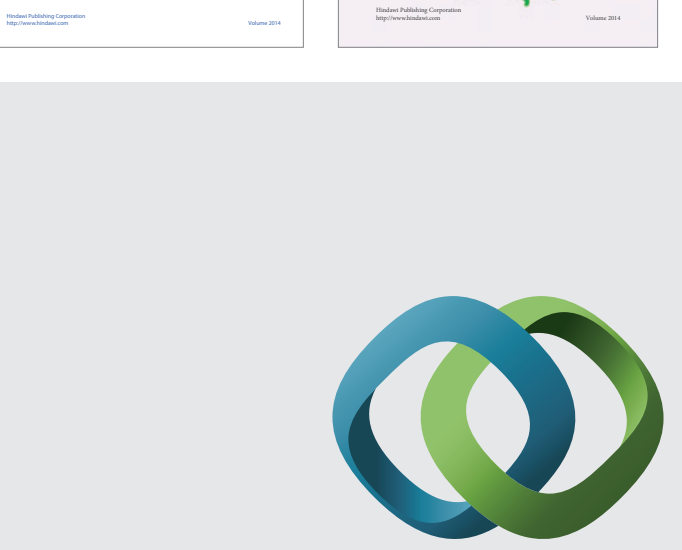

\section{Hindawi}

Submit your manuscripts at

http://www.hindawi.com
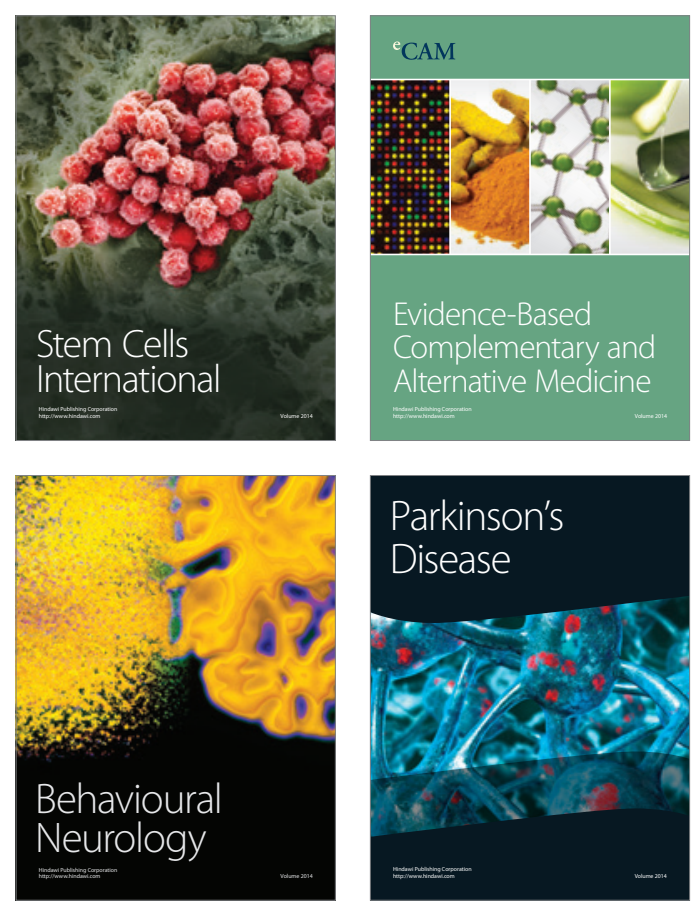

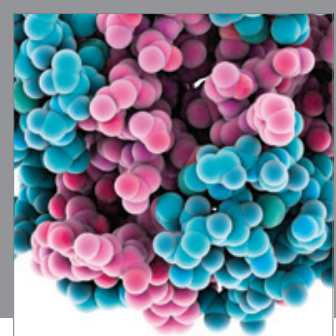

Journal of
Diabetes Research

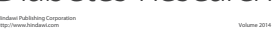

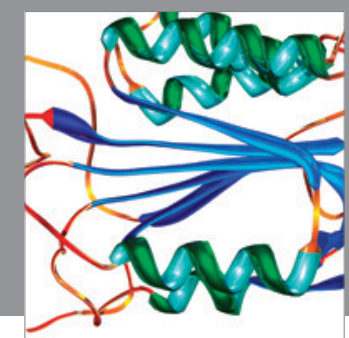

Disease Markers
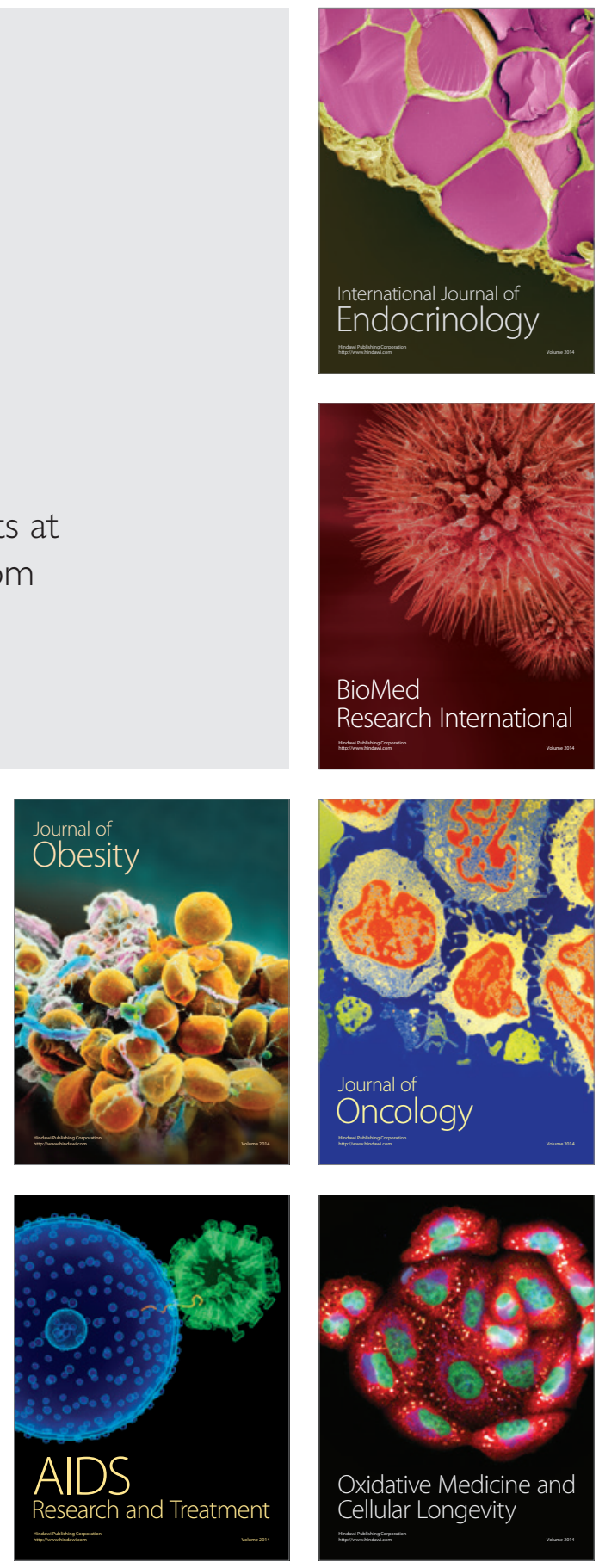